\title{
Innovation, on-the-job learning, and labor contracts: an organizational equilibria approach
}

\author{
Stefano Dughera ${ }^{1,2 *}$ (D), Francesco Quatraro ${ }^{1,3}$ and Claudia Vittori ${ }^{4}$ \\ ${ }^{1}$ University of Torino, Lungo Dora Siena 100/A, Torino, Italy, ${ }^{2}$ LABORatorio R. Revelli Centre for Employment Studies, \\ Piazza Vincenzo Arbarello 8, 10122 Torino, Italy, ${ }^{3}$ Collegio Carlo Alberto, Piazza Vincenzo Arbarello 8, Torino, Italy and \\ ${ }^{4}$ National Institute for the Analysis of Public Policies (INAPP), Corso d'Italia, 33 - 00198 Roma, Italy \\ ${ }^{*}$ Corresponding author. Email: s.dughera@unito.it
}

(Received 12 February 2021; revised 7 June 2021; accepted 7 June 2021; first published online 5 July 2021)

\begin{abstract}
An established tenet of the literature is that the use of flexible labor leads to less innovation. Yet, less attention has been paid to the possibility that it is the decision to innovate that generates the incentive to hire on a permanent basis. The goal of this paper is to show the existence of interlocking complementarities between the firm's technological and hiring strategies. To do so, we develop a simple model where the workers' decision to invest in human capital is affected by the type of employment contract (temporary versus permanent) and by the type of technological investments (routine versus innovative). When the firm is unable to coordinate its actions across these different domains, two equilibria simultaneously exist: in the 'high-road' equilibrium, firms invest more in innovative projects and hire on a permanent basis; in the 'low-road' equilibrium, they invest more in routine projects and hire on a temporary basis.
\end{abstract}

Key words: Innovation; institutional complementarities; organizational equilibria; temporary workers

JEL codes: J41; K31; M54; O3

\section{Introduction}

The ongoing flexibilization of European labor markets has received extensive attention in the literature (see, e.g. Deakin et al., 2008; Eurofound, 2020; European Commission, 2010). Although early studies advocate that flexibility promotes job creation through the reduction of firing costs (Houseman, 2001; Saint-Paul et al., 1996), recent empirical research shows that it also creates an increase in the share of precarious occupations (Boeri and Garibaldi, 2007), a downward wage pressure on permanent employees (Bellani and Bosio, 2019) and the polarization of the workers' occupational chances in both low- and high-skill jobs (Polavieja, 2005). Moreover, although many see skill-biased technological change as the main cause of the growth of wage inequality, Kristal and Cohen (2017) show that this is mostly driven by the mounting worker disempowerment rather than by market forces, at least in the USA. Complementarily, the agent-based model in Dosi et al. (2020) postulates that the competition between high-wage firms seeking to raise productivity and low-productivity firms seeking to cut wages generates the possibility of multiple equilibria. When the 'low-road' prevails, a 'winner-takes-all economy' populated by cost-minimizing firms eventually emerge, with negative repercussions on both productivity and wages. In the opposite long-lasting scenario, the society features a 'social market economy' coupling rewards for the accumulation of firm-specific skills with a more egalitarian wage structure. Finally, Collins (2006) argues that the sizeable use on temporary contracts calls for the design of new institutional solutions to ensure the workers' cooperation with these new forms of employment, which will otherwise erode both labor productivity and firm competitiveness.

(c) The Author(s), 2021. Published by Cambridge University Press on behalf of Millennium Economics Ltd. This is an Open Access article, distributed under the terms of the Creative Commons Attribution licence (http://creativecommons.org/licenses/by/4.0/), which permits unrestricted re-use, distribution, and reproduction in any medium, provided the original work is properly cited. 
In addition, the wisdom whereby greater flexibility should trigger entrepreneurship and innovation has also been challenged. It is now an established fact that innovation and technological change are key to economic growth, firms' survival, and international competition (Cefis and Marsili, 2006; Ganotakis, 2012; Kuhlmann and Edler, 2003; Slaper et al., 2011). Hence, analysis of the determinants of innovation is a major task for both economists and social scientists, in general. The extant literature has stressed the importance of firms' size, sectoral specificities, R\&D investments, and R\&D personnel as key drivers of variance in innovation outcomes both at the micro and macro levels. In addition, a growing body of research has also emphasized that good human resource management practices are key to successful innovation (e.g. Beugelsdijk, 2008; Bos-Nehles et al., 2017; Haneda and Ito, 2018; Laursen and Foss, 2003; Shipton et al., 2006). Therefore, empirical analyses have focused on the determinants of innovation in firms, countries, and regions, based, on the one hand, on the well-known knowledge production function approach (Griliches, 1984; Jaffe, 1989) and, on the other hand, on the Crépon-Duguet-Mairess model (Crépon et al., 1998).

As concerns the effect of labor market deregulation on innovation, Dilli (2019) argues that flexibility alone is insufficient to foster entrepreneurship, as an entire system of innovation-enhancing institutions is a prerequisite for successful innovation. Consistently, the literature on the variety of capitalism (hereafter, VC) has shown that the intensity and the kind of innovation pursued by an economic system depends on the multiple complementarities defining a country's institutional framework (Allen, 2013; Hall and Soskice, 2001). The intuition behind this argument is in line with early institutionalist contributions that place relative emphasis on the structural components of the so-called 'national systems of innovation' (Lundvall, 1992; Nelson, 1993; OECD, 1997). Support to such views which emphasize the institutional embeddedness of national innovative capabilities comes from Belloc (2019), who shows that aggregate innovation outcomes are positively affected by the complementarity between employment protection legislation and employee representation legislation, and Vatiero (2017), who shows that country-level innovation is spurred by the complementarity between labor laws and ownership concentration. At a more micro level, but in line with the above studies, Acharya et al. (2014) find that wrongful discharge laws and greater employment protection induce both entrepreneurs and employees to increase their innovative efforts.

More recently, a growing strand of empirical research has shown that the use of flexible labor ultimately leads to less innovation, irrespectively of the kind of innovation and of the features of the institutional framework (Altuzarra and Serrano, 2010; Dekker et al., 2011; Franceschini and Mariani, 2015; Guarascio et al., 2019; Hoxha and Kleinknecht, 2020; Kleinknecht et al., 2014; Lucidi and Kleinknecht, 2010; Malgarini et al., 2013; Michie and Sheehan, 2003; Wachsen and Blind, 2016). Although VC theorists predict that greater labor flexibility should increase a country's performance in radical innovation at the expense of incremental innovation, the above studies find that it is conversely associated with less innovation tout court, thereby suggesting a primary and negative relationship between labor market deregulation and innovation. ${ }^{1}$

The main goal of this paper is to provide with novel theoretical insights into the relationship between temporary workers and innovation. Since the extant literature has showed that the use of flexible labor is detrimental to all kinds of innovation (irrespectively of the distinction between process versus product or radical versus incremental), we develop a framework where a firm must decide whether to invest in 'routinary' projects that involve no innovative effort, or in 'innovative' activities that capture the broadest array of possible innovations. However, despite our preferred interpretation of the proposed terminology is quite radical, we believe that more moderate readings could also be applied, with 'routinary' activities capturing, for instance, incremental innovation and 'innovative'

\footnotetext{
${ }^{1}$ Incidentally, this is in line with Herrmann's (2008) critique to the VC approach to innovation, which shows that firms overcome comparative institutional disadvantages by relying on functionally equivalent institutions, such as open international labor markets and atypical contracts. In this view, the VC approach to innovation is 'too deterministic', as it overlooks the Schumpeterian role of entrepreneurs as independent creators.
} 
activities capturing radical innovation. In addition, we deem this dichotomy as being highly compatible with March's (1991) classical distinction between 'exploitation' and 'exploration', as the former involve 'routinary' activities such as refinement, efficiency, selection, implementation, and execution, whereas the latter involves 'innovative' activities such as search, variation, risk taking, experimentation, and discovery. ${ }^{2}$

More specifically, we analyze a particular kind of complementarity arising between the firms' hiring and innovation strategy. Although we do not deny the role of macro institutional constraints in the firms' innovation performance, we are interested in showing that other and more micro-founded institutional bonds also exist within the single organization. Indeed, although previous studies emphasized a direction of causality going from temporary workers to innovation - see, e.g. Kleinknecht et al. (2014) - our key contention is that that there is no reason to exclude that it is the decision to invest in innovative projects that conversely generates the incentives to hire on a permanent basis. Expanding on the growing literature on organizational equilibria and institutional complementarities (Earle et al., 2006; Gürpinar, 2016; Landini, 2013; Nicita and Pagano, 2016; Pagano, 2011; 1993; Pagano and Rossi, 2004; Pagano and Rowthorn, 1994), we thus show that these two directions of causality are not mutually exclusive, but rather, they reinforce and sustain each other.

The remainder of the paper is organized as follows. Section 2 discusses the theoretical background that is relevant for our study. In sections 3 and 4, we develop and analyze our theoretical model. Section 5 comments and concludes.

\section{Background}

\section{Organizational equilibria}

Coordinating decisions at the corporate level is a multidimensional task. Hence, organizational changes require transformations in multiple domains of the firm's strategy that are not always easy to coordinate throughout. As corporations grow in both complexity and size, in fact, they face an increasing trade-off between adaptivity and coordination (Dessein and Santos, 2006), as the greater autonomy of the individual operating units implies that each selects its strategy taking the others' as given. Hence, what appears to be a network of independent choices, is, in reality, a self-reinforcing system characterized by path-dependency and irreversibility. In this framework, an organizational equilibrium is defined as a set of interlocking elements that are kept together by the uncoordinated actions of the different decision-makers in the organization, who best-respond to each other's strategy taking the latter as given. The upshot is that when the optimal arrangement is not unique, the selection of the efficient organizational mode cannot be taken for granted.

Before the development of the literature on organizational equilibria, different strands of research put relative emphasis on elements that were supposed to be somewhat predominant in the organization of firms. Neo-institutionalists following the seminal studies of Coase (1937) and Williamson (1985), for instance, explained the emergence of efficient institutions within a world of exogenous technology. Radical political economists inspired by authors such as Marglin (1974), Braverman (1974), and Bowles (1985), in turn, claimed that it is the initial allocation of property rights over the assets used in production that chiefly determines the form and organization of firms. However, as Pagano and Rowthorn (1994) argued in their seminal contribution, both views are unsatisfactory, as organizations are not technological units that operate in an institutional vacuum, and neither, they are 'nexuses of contracts and organizational rules' that produce free of technological constraints. When both technology and institutions constitute endogenous and independent domains of choice, in fact, one cannot overlook the influence they exert over each other.

The idea that there are complementarities among the elements of firms' strategy was first introduced by Milgrom and Roberts (1990) and later conceptualized in terms of institutional

\footnotetext{
${ }^{2}$ To some extent, the classical distinction between general-purpose (routinary) and transaction-specific (innovative) may also apply. Since our focus, however, is on innovation, we believe that the proposed terminology is more clear-cut.
} 
complementarities by Aoki (1994). ${ }^{3}$ In the same year, Pagano and Rowthorn (1994) showed the existence of a two-way relation between technology and property rights. Thereafter, a growing body of research applied the notion of organizational equilibrium to a variety of different domains, identifying interlocking complementarities within the domain of information production (Landini, 2013), between technology and finance (Nicita and Pagano, 2016), intellectual property rights and cognitive labor (Gürpinar, 2016), unionization and job-automation (Belloc et al., 2020) and, at a higher level of the economy, between ownership concentration and the emergence of systems of worker representation (Landini and Pagano, 2018a, 2018b). The notion of organizational equilibrium has proven insightful to explain the emergence and persistence of different organizational forms that endure over time in spite of their inefficiency, and thus, that it can be used as a valid tool to formulate policy recommendations.

\section{Temporary workers and innovation}

Evolutionary economics stresses the importance of organizational learning and tacit knowledge for the introduction of change in firms and sectors (Nelson and Winter, 1982). In line with the resourcebased view of the firm, on-the-job learning is deemed to be a necessary requirement for the generation of tacit knowledge, that, in turn, stands as an antecedent for the emergence of new organizational and technical knowledge (Foss, 1997; Penrose, 1959). In this framework, innovation depends on the combination of formalized R\&D and unformalized on-the-job learning. Grinza and Quatraro (2019: 7) find support to this hypothesis by showing that workers' replacements have a negative effect on the number of patent applications, consistently with the idea that 'when workers leave, they take with them firm-specific knowledge about competencies and routines, as well as about the potential for resource combination for the creation of novelty'.

Hence, since human capital accumulation requires long-lasting processes of organizational learning that involve a two-way exchange between the organization and its personnel (Schneider et al., 2010), or, to put it differently, between routines and individual skills, it comes as no surprise that the available evidence is almost unanimous in claiming that the use of temporary workers is detrimental to innovation - see, e.g. Hoxha and Kleinknecht, (2020); Guarascio et al. (2019); Wachsen and Blind (2016); Franceschini and Mariani (2015); Kleinknecht et al. (2014); Malgarini et al. (2013); Dekker et al. (2011); Lucidi and Kleinknecht (2010); and Michie and Sheehan (2003). Opposite predictions, however, come from Arvanitis (2005), whereas Altuzarra and Serrano (2010) find a non-monotonic relationship between labor flexibility and innovation. In their study, the firms employing only permanent workers have the lowest propensity to innovate, but the probability of filing a successful innovation decreases as the rate of fixed-term workers increases beyond the innovation-compatible threshold.

Given the above, it must be the case that some kind of mechanism is at play when it comes to the effect of labor contracts on worker learning. The starting point is that a key but often forgotten requirement for workers to invest in human capital is their willingness to learn. As rightfully recalled by Kräkel (2016: 627), in fact,

traditional human capital theory assumes that a worker has no choice whether to acquire knowledge or not. When a firm decides to invest in human capital, a worker is considered more like a robot to be programmed rather than a human being who is free to learn or not. Often, however, such programming is not possible.

Once we acknowledge this strategic dimension of learning, we must also recognize its pivotal role around which to design the work incentives to spur innovation. Although principal-agent models have been mainly studying the innovation-motivating contract that directly induce agents to innovate (see, e.g. Manso, 2011), our point is more subtle, as we are interested in understanding how different labor contracts may lead to different patterns of skill accumulation and learning dynamics, that, in

\footnotetext{
${ }^{3}$ For more general appraisals of the role of institutional complementarities in economic systems, see Aoki (2001) and Pagano and Vatiero (2015).
} 
turn, indirectly affect the firms' decision to innovate. The starting point is that innovation is mostly firm-specific, and so are the skills required to carry it through. Hence, since temporary workers are not interested in acquiring capabilities that do not increase their employability on the job market (Belot et al., 2007), flexible labor contracts match poorly with investments in firm-specific human capital, and thus, by extension, with innovation.

Given this strategic dimension of learning, two routes can be identified to explain the evidence whereby firms relying heavily of temporary contracts innovate less. The first avenue suggests that it is the use of flexible labor that ultimately leads to less innovation. This is the view that received the greatest attention by the extant literature (see, e.g. Kleinknecht et al., 2014). In this framework, the firms that decide to cut on labor costs or to increase the share of easily dismissible workers, end up innovating less because of their workers' unwillingness to invest in human capital, although this is simply a byproduct of their 'low-road' human resource management strategy. This is also consistent with the 'efficiency-wage' theory, according to which employees' effort, including the innovative one, is a positive function of wages (Akerlof and Yellen, 1986; Antonelli and Quatraro, 2013; Shapiro and Stiglitz, 1984).

The opposite view postulates that it is the decision to invest in innovative projects that conversely generates the incentives to hire on a permanent basis. Anticipating that workers will acquire firmspecific skills only if offered a permanent contract, firms may find it rational to recruit on a permanent basis to provide greater learning incentives as to improve their innovation performance. In the first case, a prominent direction of causality going from institutions to technology, that is, from labor contracts to innovation, is identified, whereas the second argument puts relative emphasis on the role of innovation in the firm's decision to hire on a permanent basis. When both causations simultaneously exist, however, not only they are not mutually exclusive, but they sustain and reinforce each other, thus generating the possibility of multiple equilibria in the firm's strategy.

\section{Labor contracts}

'Institutions - according to North's (1990: 3-4) classical definition - are the rules of the game in a society or, more formally, are the humanly devised constraints that shape human interaction [...] institutions define and limit the set of choices of individuals'. Labor law, in this respect, is no different: it defines the rules that govern the labor market. In doing so, it creates macro institutional bonds that constrain the behavior of all types of employers and employees, as well as a menu of microinstitutional solutions that provide organizations with some freedom in choosing the arrangement which is best fitting with their needs. In this framework, the different types of contracts envisaged by a nation's labor law can be viewed as micro-institutional arrangements that impose an array of specific conditions on a given employment relationship. In doing so, not only they formally define the set of jural relations bonding together employers and employees, but they also informally affect the workers' behavior. According to the viewpoint of industrial psychologists and sociologists, in fact, there exists an implicit psychological contract between principal and agents (see, e.g. Ribeaux and Poppleton, 1978; and Beer et al., 1984). In this view, permanent contracts can be seen as a signal of trust that promotes long-term commitment and human capital accumulation (Lorenz, 1999; Michie and Sheehan, 2001, 2003; Svensson, 2011).

In this respect, 'the liberalisation of temporary contracts [...] has been the main labour market reform in continental Europe during the last decades' (Berton and Garibaldi, 2012: F125), as it provided employers with a new institutional tool designed to satisfy the growing need for adaptivity created by an increasingly turbulent economic environment (see, e.g. Deakin et al., 2008; Eurofound, 2020; European Commission, 2010). The distinctive trait of temporary contracts, as it is well-known, is that of providing firms with greater flexibility in downsizing, which is something that can be crucial in the case of unanticipated changes in the outside economic conditions. Advocates of the 'flexibility argument' have widely insisted on the idea that adaptivity is a key requirement to improve organizational performance (Bassanini and Ernst, 2002; Scarpetta and Tressel, 2004). The step from flexibility 
to precariousness, however, can be short. Indeed, although countries like Holland and Denmark have been proven successful in coupling the liberalization of temporary contracts with flexicurity systems that provide workers with income support during unemployment spells (OECD, 1997), countries like Italy have been proven less virtuous in this regard (Berton et al., 2012).

The institutional trade-off we study in this paper is simple, although strictly related to the above discussion. In the theoretical model developed in section 3, we assume that temporary contracts can be broken at no cost upon the arrival of an adverse (and exogenous) productivity shock. In addition, we show that there exist situations where permanent contracts generate incentives for workers to invest in human capital that are absent in the case of temporary contracts. In this framework, a highroad/low-road tale endogenously emerges, since firms may either decide to increase their flexibility and rely on temporary contracts or seize the gains from human capital by recruiting on a permanent basis.

\section{The model}

\section{Timing and setup}

In this section, we develop a two-stage game where a project $(P)$ and a human resource manager $(H)$ hire a set of additional employees (individually indicate as $E$ ) to run their business. Workers are assumed to be ex-ante identical in terms of capabilities, bargaining power, and outside option. Hence, they receive a uniform wage $w>0$ which does not vary across the different labor contracts, which however provide different levels of employment protection. We assume that $w$ satisfies the workers' participation and incentive compatibility constraint, so that all workers find it rational to enter the labor market and exert the required level of effort. The timing of a typical period is as follows.

At stage $1, P$ and $H$ make separate choices taking each other's as given. In this framework, complementarities may arise because of the managers' inability to coordinate their actions. ${ }^{4,5}$ In the technological domain, $P$ selects a project portfolio comprising an optimal mix of 'routinary' $(R)$ and 'innovative' $(I)$ activities, whereas, in the institutional domain, $H$ chooses between temporary $(T)$ and open-ended $(O)$ contracts. All projects last for one period, at the end of which, wages are paid, and profits are collected.

At the beginning of stage 2, workers decide how intensively to invest in human capital, depending on its portability latter and on the size of learning costs. After that, all employees exert effort, revenues are collected, and the game ends. During the production phase, the economy experiences an adverse productivity shock with exogenous probability $0<s<1$. In this case, all projects are aborted and yield zero payoff. ${ }^{6}$

To model the idea that labor flexibility allows firms to adjust easily to the outside economic environment, we assume that temporary workers can be dismissed at no cost, whereas permanent workers must be compensated with a severance payment that is exogenously set by the labor law. To keep things simple, we assume that this indemnity is large enough so that firms find it rational not to dismiss their permanent workers upon the arrival of the productivity shock. This admittedly limiting assumption allows us to focus on a trade-off that is quite common in contemporary labor markets: although permanent contracts may promote organizational performance in several ways (in our

\footnotetext{
${ }^{4}$ This is a key assumption of the model. In the absence of such coordination problem, in fact, the two managers would select the combination of project and labor contracts that maximizes their joint profits. In this case, our model would still allow for different equilibrium outcomes, despite all resulting equilibria would be unique.

${ }^{5}$ In principle, there are no reasons to exclude that a similar coordination problem may also exist between independent contractors. Imagine a value chain where an upstream producer (call her A) takes charge of the early phases of a productive project (concept, $\mathrm{R} \& \mathrm{D}$, branding, and designing) and outsources its implementation to a downstream organization (call her B). In this case, A may find it rational to invest in the refinement of an existing product rather than in the development of a new one when observe that B recruits on a temporary basis, as the overall success of the joint production depends on the relative efficiency of both $\mathrm{A}$ and $\mathrm{B}$.

${ }^{6}$ The assumption of stochastic productivity shocks is common in labor market models dealing with temporary and permanent contracts - see, for instance, Berton and Garibaldi (2012).
} 
case, by inducing workers to invest in human capital), flexible tenures allow firms to adapt to unanticipated changes in the outside economic environment. The game is solved by backward induction. Since employees are identical, we will analyze the workers' human capital investment by referring to a representative employee $E$ (she).

\section{Stage 2: human capital investments}

$E$ lives for two periods, $t_{1}$ and $t_{2}$. In each period, she works on a single project chosen by $P$. Our working assumption is that the different types of projects require different skill-sets. More specifically, we assume that $R$-projects require only general skills, whereas $I$-projects require a mix of general and firm-specific skills. The underlying idea is that routinary activities are similar across firms, whereas innovation is more specific. To keep things simple, we assume that workers cannot invest differentially in the skills composing each set, but can only fine-tune the intensity with which they acquire the entire module of human capital.

At stage 2, $E$ works under a given labor contract (temporary versus permanent) chosen by $H$ at stage 1 . When the contract is open-ended, $E$ remains with $H$ in both $t_{1}$ and $t_{2}$. Conversely, temporary contracts last for one period, so that $E$ enters the unemployment pool at the beginning of $t_{2}$. In this case, she finds another job with probability $0<a<1$. When unemployed, she receives her outside option, which we normalize to zero. In addition, recall that temporary workers have a probability $0<s<1$ of being separated from their jobs due to the arrival of an adverse productivity shock. In this case, they remain unemployed for the period and lose their human capital investments. For the sake of simplicity, we assume that $E$ has no incentive to leave $H$ along the entire duration of the labor contract.

At the beginning of $t_{1}, E$ decides how intensively to invest in human capital depending on the learning incentives generated by different combinations of projects and labor contracts. More specifically, we borrow from the field of educational psychology (Marton and Säljö, 1976) and assume that $E$ chooses between two learning strategies, 'deep' $(\lambda=1)$ and 'surface' $(\lambda=0)$ learning. In the first mode, she adopts an affirmative learning attitude to understand the meaning of her assignment and acquire the skill-set in full. The second mode involves a learning performance of a minimally acceptable sort. The underlying assumption, in this case, is that deep-learning is costlier than surface-learning.

As in Kräkel (2016), we assume that learning reduces the cost of effort when $E$ works for $H$. In addition - and always in line with Kräkel (2016) - we assume that $E$ may be able to recover some of her human capital investments in $t_{2}$, depending on the degree of portability (or generality) of the acquired skills. ${ }^{7}$ Formally, we assume that the cost of effort is defined over an interval $\left[e_{L}, e_{H}\right]$. For future reference, define $e_{H}-e_{L}=e>0$. Given this, a temporary worker chooses $\lambda \in\{0,1\}$ to maximize:

$$
U_{T}^{J}(\lambda)=(1-s)\left[w-e_{H}+\left(e_{H}-e_{L}\right) \lambda\right]+r(1-s) a\left[w-e_{H}+p^{J}\left(e_{H}-e_{L}\right) \lambda\right]-c \lambda
$$

where the superscript $J \in\{I, R\}$ denotes the type of project and the subscript $T$ the type of labor contract, whereas $0<r<1$ is the discount rate. The terms in the first square (resp., second) brackets on the right-hand side of equation (1) measure E's payoff in $t_{1}$ (resp., $t_{2}$ ). $c \geq 0$, in turn, is the cost of deep-learning. For simplicity, the cost of surface-learning is normalized to zero. Finally, $0 \leq p^{J} \leq 1$, $J \in\{I, R\}$ captures the portability of the skill-set associated with the different projects. To model the idea, the skills acquired in 'innovative' projects are less portable than those acquired in 'routinary' projects, we assume that $0 \leq p^{I} \leq p^{R} \leq 1$.

Our first assumption, that learning reduces the cost of effort when $E$ works for $H$, is captured by the term $-(1-s)\left[e_{H}-\left(e_{H}-e_{L}\right) \lambda\right]$, where the cost of effort in $t_{1}$ is specified as a decreasing function of $\lambda$.

\footnotetext{
${ }^{7}$ We rule the possibility that $E$ is intrinsically motivated to learn. In that case, workers assigned to innovative projects may have extra incentives to invest in human capital, as getting involved in innovation could be intrinsically more rewarding than perform a routinary activity. Even if this channel is taken into account, however, our results remain unchanged.
} 
Table 1. Worker's payoffs

\begin{tabular}{ll}
\hline Parameter & Interpretation \\
\hline $0 \leq s \leq 1$ & Arrival rate of productivity shocks \\
\hline $0<r<1$ & Workers' discount rate \\
\hline $0<a<1$ & Job-acquisition rate \\
\hline$w>0$ & Uniform wage \\
\hline$\left[e_{L}, e_{H}\right]$ & Effort cost \\
\hline$c \geq 0$ & Learning cost \\
\hline$p^{\prime} \leq p^{R} \leq 1$ & Portability of the skills involved in routinary projects \\
\hline $0 \leq p^{\prime} \leq p^{R}$ & Portability of the skills involved in innovative projects \\
\hline$\lambda \in\{0,1\}$ & E's decision variable $\lambda=\left\{\begin{array}{l}1 \text { in case of deep learning } \\
\end{array}\right.$ \\
\hline
\end{tabular}

Our second assumption, that the skills acquired in a given project may be portable outside the firm, is captured by the term $-r(1-s) a\left[e_{H}-p^{J}\left(e_{H}-e_{L}\right) \lambda\right]$, where the expected cost of effort in $t_{2}$ is specified as a decreasing function of $\lambda$ and $p^{J}$. Similarly, a permanent worker chooses $\lambda \in\{0,1\}$ to maximize:

$$
U_{O}^{J}(\lambda)=\left[w-e_{H}+\left(e_{H}-e_{L}\right) \lambda\right]+r\left[w-e_{H}+\left(e_{H}-e_{L}\right) \lambda\right]-c \lambda
$$

The interpretation of equation (2) is analogous to equation (1). For a summary of the parameters' interpretation, see Table 1 .

Given the above, it should be clear that the incentives to invest in human capital crucially depends on the size of the learning cost $c$, on the portability of the acquired skills $p^{J}$ and on the job-acquisition rate $a$, as put forward by the following lemma ${ }^{8}$ :

Lemma 1. A temporary worker assigned to an innovative project invests in deep-learning if $c \leq e(1+$ $\left.\operatorname{arp}^{I}\right)$. In addition, a temporary worker assigned to a routinary project invests in deep-learning if $c \leq$ $e\left(1+\operatorname{arp}^{R}\right)$. Finally, a permanent worker invests in deep-learning if $c \leq e(1+r)$, regardless of the type of project.

Observe that the critical threshold $e(1+r)$ is the greatest among the three derived in Lemma 1, which implies that the range of learning costs that allows workers with an open-ended contract to invest in deep-learning is always larger than that of temporary workers. In simple words - thought somewhat imprecisely - it could be said that it is 'more likely' that permanent worker invests in deep-learning. This is due to the fact that all types of skills are assumed to be entirely portable when remaining within the firm and thus, that permanent workers benefit from their human capital investments along the entire duration of their occupational life $\left(t_{1}+t_{2}\right)$. In addition, given the assumption that the skill-set involved in innovative projects is not easily portable outside the firm $\left(p^{I}<p^{R}\right)$, the range of learning costs that makes deep-learning viable for temporary workers is always larger when they are assigned to routinary projects. As before, this implies that is 'more likely' that a permanent worker invests in deep-learning when working on a routinary project.

Figure 1 visualizes the results of Lemma 1 and makes clear that the decision to invest in deep-learning crucially depends on the value of $c$. There are several mechanisms which may affect

${ }^{8}$ All proofs are collected in the Appendix, which is available from the authors upon request. 


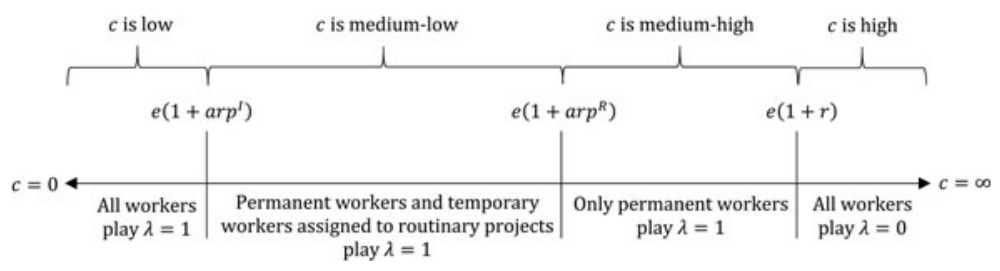

Figure 1. Learning incentives.

the cost of learning. For instance, $c$ could increase with task complexity or decrease with the workers' intrinsic motivation to learn.

\section{Innovative versus routinary projects}

At stage 2, $P$ composes a project portfolio by selecting the optimal quantity of innovative and routinary activities, denoted, respectively, as $I>0$ and $R>0$. We assume that the technological costs of investing in innovative and routinary projects are described by the convex cost function $K(I, R)$, where $K(0,0)=$ $0, \partial K / \partial J>0$, and $\partial^{2} K / \partial^{2} J>0, J \in\{I, R\}$. All projects last for one period, require a single unit of labor, and can be more or less successful, depending on the workers' investment at stage 2. To keep things simple and focus on the relationship between human capital and productivity, we assume that both types of projects are fully successful when workers invest in deep-learning, whereas they yield a truncated return when workers invest in surface-learning. ${ }^{9}$ More specifically, we assume that $I$-projects yield a payoff equal to $A>0$ when $\lambda=1$, and a payoff equal to $D>0$ when $\lambda=0$. Similarly, $R$-projects yield a payoff equal to $B>0$ when $\lambda=1$, and a payoff equal to $C>0$ when $\lambda=0$. To model the idea that $I$-projects are riskier but potentially more profitable than $R$-projects, we follow Acharya et al. (2014) and assume that $0<D<C<B<A$. Finally, recall that in the case of a productivity shock, all projects are aborted and yield zero payoffs. Hence, each activity can be in three states: a 'highstate' occurring with probability $(1-s) \lambda$, a 'middle-state' occurring with probability $(1-s)(1-\lambda)$, and a 'low-state' occurring with probability $s$.

To ensure the viability of open-ended contracts, we assume that $H$ finds it rational to recruit on a permanent basis when open-ended contracts provide workers with learning incentives that are not generated by temporary contracts. This amounts to assuming that when permanent contracts yield $\lambda=1$ and temporary contracts yield $\lambda=0$, permanent contracts yield higher payoffs in both routinary and innovative activities. Hence, we formulate the following assumption:

Assumption 1. The probability of adverse productivity shocks is not so high to make permanent contracts irrational. Parametrically, this corresponds to $s \leq(B-C) /(B-C+w) \equiv \hat{s}$.

\section{Results}

\section{Profit functions and decision rules}

Assume that $H$ and $P$ split the operating profit 50:50. In this case, the managers' profits are given by:

$$
\begin{gathered}
\Pi_{O}(R, I)=\frac{1}{2}\{(1-s)[\lambda A+(1-\lambda) D] I+(1-s)[\lambda B+(1-\lambda) C] R-(I+R) w-K(I, R)\} \\
\Pi_{T}(R, I)=\frac{1}{2}\{(1-s)[\lambda A+(1-\lambda) D-w] I+(1-s)[\lambda B+(1-\lambda) C-w] R-K(I, R)\}
\end{gathered}
$$

\footnotetext{
${ }^{9}$ Alternatively, we may assume that $E$ produces valuable output with probability $y(\lambda)$ and zero output with probability $1-y(\lambda)$, where $E$ 's learning decision affects positively the success probability so that $1>y(1)>y(0)>0$. Despite more realistic, this specification adds little to our results.
} 
Given the assumption that temporary workers can be dismissed at no cost upon the arrival of a productivity shock, the wage payments in equation (4) are paid with probability $1-s$, whereas those in equation (3) are paid with probability $=1$, since they are independent from the economy's exogenous state. The decision rules that define the managers' equilibrium strategy are as follows. When $H$ hires on a permanent basis, $P$ maximizes equation (3) with respect to $I$ and $R$. Denote $I_{O}$ and $R_{O}$ as the arguments that maximize $\Pi_{O}$. Conversely, when $H$ hires on a temporary basis, $P$ maximizes equation (4) with respect to $I$ and $R$. Denote $I_{T}$ and $R_{T}$ as the arguments that maximize $\Pi_{T}$. Whether $I_{i}$ will be higher or lower than $I_{j}$, of course, depends on the employees' decision at stage $1, i \in\{I, R\}$ and $i \neq j$.

$H$, in turn, takes $P$ 's decision as given and chooses the type of labor contract that provides the higher returns. Hence, applying a tie-breaking rule whereby $H$ chooses to hire on a permanent basis when $\mathrm{s} / \mathrm{he}$ is indifferent between the two types of labor contract, s/he plays $O$ when $\Pi_{O}\left(I_{O}\right.$, $\left.R_{O}\right) \geq \Pi_{T}\left(I_{T}, R_{T}\right)$ and plays $T$ when $\Pi_{T}\left(I_{T}, R_{T}\right)>\Pi_{O}\left(I_{O}, R_{O}\right)$.

\section{Organizational equilibria}

When $H$ recruits on a permanent basis, $P$ maximizes equation (3) with respect to $I$ and $R$. In this case, the first-order conditions for optimal profit are given by:

$$
\begin{aligned}
& \frac{\partial \Pi_{O}}{\partial I}=(1-s)[\lambda A+(1-\lambda) D]-w-\frac{\partial K(I, R)}{\partial I}=0 \\
& \frac{\partial \Pi_{O}}{\partial R}=(1-s)[\lambda B+(1-\lambda) C]-w-\frac{\partial K(I, R)}{\partial R}=0
\end{aligned}
$$

where $\left(I_{O}, R_{O}\right)$ describes the firm's technology when $H$ hires on a permanent basis. For future reference, define the firm's technology as $T_{O} \equiv I_{O} / R_{O}$.

Similarly, when $H$ recruits on a temporary basis, $P$ maximizes equation (4) with respect to $I$ and $R$. In this case, the first-order conditions for optimal profit are given by:

$$
\begin{aligned}
& \frac{\partial \Pi_{T}}{\partial I}=(1-s)[\lambda A+(1-\lambda) D-w]-\frac{\partial K(I, R)}{\partial I}=0 \\
& \frac{\partial \Pi_{T}}{\partial R}=(1-s)[\lambda A+(1-\lambda) D-w]-\frac{\partial K(I, R)}{\partial R}=0
\end{aligned}
$$

where $\left(I_{T}, R_{T}\right)$ describes the firm's technology when $H$ hires on a temporary basis. As before, define $T_{T} \equiv I_{T} / R_{T}$. The larger (resp., smaller) is $T_{i}, i=T, O$, the more 'innovative' (resp., 'routinary') is the project portfolio.

To characterize the equilibrium outcomes of the game, we will proceed in two steps. Proposition 1 analyzes the case where the manager's choices are independent from one another; Proposition 2 those characterized by interlocking complementarities and multiple equilibria.

Proposition 1. When learning costs are either high, low, or medium-high, P's and H's choices are independent. In this case, a unique equilibrium where $H$ recruits on a temporary basis exists if learning costs are either high $-c>e(1+r)-$ or low $c<e\left(1+\right.$ rap $\left.{ }^{I}\right)$. Similarly, a unique equilibrium where $H$ recruits on a permanent basis exists if learning costs are medium-high $-e\left(1+r a p^{R}\right)<c<e(1+r)$.

In the first and second scenarios allowed for by Proposition 1, workers choose the same learning strategy regardless of the type of project and labor contract. Indeed, when $c$ is small (resp., large), all 
workers find it rational to invest in deep-learning (resp., surface-learning). In this case, $H$ chooses the tenure that provides the greatest flexibility in downsizing, whereas $P$ composes the project portfolio according to the different returns generated by the workers' decision. ${ }^{10}$ In the third scenario, only permanent workers invest in deep-learning, regardless of the type of project, and thus, according to Assumption 1, permanent contracts yield higher payoffs than temporary contracts in both routinary and innovative activities. In this case, $H$ recruits on a permanent basis, whereas $P$ composes a project portfolio reflecting the fact that workers invest in deep-learning across both types of activities.

Proposition 2. When learning costs are medium-low $-e\left(1+r a p^{I}\right)<c<e\left(1+r p^{R}\right)-H$ 's hiring decisions and P's technological choice are characterized by interlocking complementarities. In this case, a unique 'high-road' equilibrium where $P$ invests relatively more in innovation and $H$ recruits on a permanent basis exists if $\bar{s} w /(A-D-\bar{s} w)<T_{T}$, where $\bar{s}=s /(1-s)$. Conversely, a unique 'low-road' equilibrium where $P$ invests relatively more in routinary projects and $H$ recruits on a temporary basis exists if $T_{O}<\bar{s} w /(A-D-\bar{s} w)$. Finally, when $T_{T}<\bar{s} w /(A-D-\bar{s} w)<T_{O}$, multiple equilibria may exist. The threshold $\bar{s} w /(A-D-\bar{s} w)$ is increasing in the probability of adverse probability shocks.

When learning costs are medium-low, permanent workers invest in deep-learning regardless of the type of project, whereas permanent workers invest in deep-learning only when assigned to routinary projects. In this case, firms relying on atypical contracts perform better in routinary activities, since they reap the same productivity gains as those recruiting on a permanent basis but downsize more flexibly in the case of productivity shocks. Conversely, firms relying on permanent contracts have a comparative advantage in innovative activities, since, according to Assumption 1, the gains from successful innovation are large enough to offset the 'rigidity' of permanent contracts. Hence, when the threshold $\bar{s} w /(A-D-\bar{s} w)$ falls in the interval $\left(T_{T}, T_{O}\right), H$ 's and $P$ 's choices are mutually reinforcing. In this case, initial conditions matter, as both the technological and the institutional architecture of the firm loom large on the managers' future decisions. Interestingly, a sort of high-road/low-road story (Kochan and Osterman, 1994) endogenously emerges, as those who innovate more also recruit on a permanent basis. However, as the last part of Proposition 2 makes clear, a unique 'low-road' equilibrium is more likely to occur when productivity shocks arrive frequently, since $H$ finds it relatively more appealing to fine-tune the firm's adaptivity to the turbulence of the outside economic environment.

\section{Welfare}

To characterize the Pareto-ranking of our multiple equilibria, we need to compare the operating profit of the firm and the utility of the representative employee across the 'high-road' and 'low-road' equilibria. To do so, we need to make specific assumptions on the functional form of $K(I, R)$. To keep things simple, we assume that $K(I, R)=\left(I^{2}+R^{2}\right) / 2$. Hence, given the employees' strategy to invest in human capital when learning cost are medium-low - see Lemma 1 - we can write the firm's profit as:

$$
\begin{aligned}
& \Pi_{O}(R, I)=[(1-s) A-w] I+[(1-s) B-w] R-\left(I^{2}+R^{2}\right) / 2 \\
& \Pi_{T}(R, I)=(1-s)(D-w) I+(1-s)(B-w) R-\left(I^{2}+R^{2}\right) / 2
\end{aligned}
$$

the maximization of which yields the following sets of optimal solutions: $\left(I_{O}, R_{O}\right)=\{(1-s) A-w,(1-s)$ $B-w\}$ and $\left(I_{T}, R_{T}\right)=\{(1-s)(D-w),(1-s)(B-w)\}$. Plugging these in equations (9) and (10), we derive

\footnotetext{
${ }^{10}$ More specifically, $P$ 's portfolio is more innovative (resp. routinary) when learning costs are low (resp. high). This is due to the assumption that $I$-projects (resp. $R$-projects) are more profitable than $R$-projects (resp., $I$-projects) when $\lambda=1$ (resp., $\lambda=0$ ).
} 
the firm's equilibrium profit, which are given by:

$$
\begin{gathered}
\Pi_{O}(R, I)=\frac{1}{2}[(1-s) A-w]^{2}+\frac{1}{2}[(1-s) B-w]^{2} \\
\Pi_{T}(R, I)=\frac{1}{2}(1-s)^{2}(D-w)^{2}+\frac{1}{2}(1-s)^{2}(B-w)^{2}
\end{gathered}
$$

Hence, we can put forward the following proposition:

Proposition 3. When multiple equilibria exist, workers are always better off in the 'high-road' equilibrium. Moreover, the two managers are better off in in the 'high-road' equilibrium iff $\Pi_{O}(R, I) \geq \Pi_{T}(R$, I), that is, iff:

$$
[(1-s) A-w]^{2}+[(1-s) B-w]^{2}>(1-s)^{2}\left[(D-w)^{2}+(B-w)^{2}\right]
$$

Hence, when condition (13) is satisfied, the high-road equilibrium Pareto-dominates the low-road equilibrium.

\section{Policy implications and institutional reforms}

Proposition 3 makes clear that the 'high-road' equilibrium is the only candidate to be Pareto-superior. Therefore, when condition (13) is satisfied but the system has gravitated toward the 'low equilibrium' due to adverse initial conditions or poor equilibrium selection, both the managers and their employees are stuck in what may be called an 'organizational poverty trap'.

This can be used as a policy argument against the plea for deregulation that has characterized the public debate over the last couple of decades or so. If our reasoning is correct, in fact, the liberalization of temporary contracts not only has negative repercussions on worker well-being, which is somewhat unsurprising, but it also endangers innovation and profitability, conversely to what suggested by the advocates of the 'flexibility thesis' (Bassanini and Ernst, 2002; Houseman, 2001; Saint-Paul et al., 1996; Scarpetta and Tressel, 2004). Flexicurity systems, in this view, perform no better. Indeed, they can do little to incentivize the accumulation of firm-specific human capital that promotes innovation (Foss, 1997; Leiponen, 2005; Penrose, 1959), despite they are crucial to protect workers from the otherwise detrimental effects of deregulation. Despite more protected workers survive better to unemployment spells, in fact, social security systems have no effect on their decision to acquire firm-specific skills, which crucially depends on the length of time they remain within a given organization. In this view vein, we can expect lifelong training programs - that constitute another key pillar of flexicurity systems - to have little, albeit positive, effects on innovation, as they usually encourage the accumulation of general skills that are insufficient to boost the creation of novelty, provided, of course, that our reasoning is correct. Since the key determinant of the workers' decision to accumulate firmspecific knowledge is the length of time they will remain within the firm, permanent contracts seem the only institutional arrangement capable of incentivizing human capital formation and innovation. The policy suggestion that can be derived is rather straightforward: institutional reforms aimed at improving labor market flexibility should be discouraged, even when they are supported by the design of flexicurity systems that increase social security. In addition, given the interlocking character of institutional complementarities, interventions in labor market institutions are ineffective unless they are coupled with the fine-tuning of innovation incentives. As recalled by Moretti and Wilson (2014) and Chirinko and Wilson (2008), in fact, investment tax incentives and place-based subsidies can be crucial to spur innovation-based clusters. Hence, providing workers with the right incentives to invest in human capital can be useless unless firms are given similar incentives to innovate. If either of the two policies is implemented without the other, the system may remain stuck in an 'organizational poverty trap' due to self-reinforcing character of organizational equilibria. 
Of course, when competition is efficient, the selective pressure should be such that the least productive firms are driven off the market. However, given the wide evidence that a variety of different corporate 'species' actually co-exists in our contemporary economies (see, e.g. Landini and Pagano, 2018a, 2018b), when market mechanisms work poorly, firms relying heavily on temporary workers and routinary projects are likely to survive. Hence, despite this paper does not provide explicit insights concerning the role of market competition in firm survival and organizational diversity, it shows that interlocking complementarities at the firm level may provide an explanation to the coexistence of different organizational forms. In this view, the paper could be extended to include a 'competition stage' that analyzes how market mechanisms may allow the selection of the most efficient form of corporate governance. We leave this possibility for future research.

\section{Conclusions}

In this paper, we have shown the existence of interlocking complementarities between the firms' decision to innovate and its choice to hire on a permanent basis. By analyzing how different types of labor contracts (temporary versus permanent) and different types of projects (routinary versus innovative) generate different learning incentives for workers to invest in human capital, we have highlighted a strategic dimension of learning that has major implications for firm-level innovation. Under given parameterizations, in fact, we have found that two organizational equilibria simultaneously exist. In the 'high-road' equilibrium, the human resource manager finds it rational to hire on a permanent basis given the project manager's decision to invest relatively more in innovation. Conversely, in the 'low-road equilibrium', the human resource manager finds it rational to hire on a temporary basis given the project manager's decision to invest relatively more in routinary activities. In addition, we have derived conditions under which the 'high-road' equilibrium is Pareto-efficient for both the organization and its personnel, whereas we have proven that the 'low-road' equilibrium is always Pareto-inefficient. The upshot is that the inability of the two managers to coordinate their strategies may lead the system to gravitate toward what we call an 'organizational poverty trap', with negative repercussions for both profitability and worker well-being. Given the self-reinforcing character of organizational equilibria, the policy implication is that regulation-induced changes in labor market institutions have little or no effect on the firms' innovation performances unless they are coupled with the fine-tuning of innovation incentives, and vice-versa, that regulatory interventions aimed at influencing the firms' technological investment will be useless without complementary maneuvers in the regulation of labor markets.

The peculiar kind of complementarity analyzed in this paper is just one among the many structural interdependencies that characterize our economic systems. Indeed, our results pave the way to further research avenues. First, our framework could be used to investigate the so-called 'meta institutional complementarities' like those analyzed by Landini and Pagano (2018a, 2018b) and bridge together the results of this paper with those identified by the remainder of the literature on organizational equilibria. In the same vein, it would be interesting to analyze how the macro-complementarities identified by VC theorists (see e.g. Allen, 2013; Hall and Soskice, 2001) interact with the micro-complementarities analyzed in this paper. Second, we have assumed a uniform wage, irrespectively of the type of labor contract. However, theoretical and empirical literature stresses that one should expect earnings for permanent and temporary workers to be different (see, e.g. Damiani et al., 2020). An extension of the model to address these wage differentials would be therefore particularly important. Third, although the proposed dichotomy between routinary and innovative activities has been viewed in a radical perspective (i.e. any innovation versus no-innovation at all), it would be interesting to apply our reasoning to other and more subtle dichotomies, such as those between incremental and radical innovation or process and product innovation. We leave this possibility for future research.

Acknowledgements. The authors thank Cristiano Antonelli, Fabio Landini, Ugo Pagano, Massimiliano Vatiero, and Filippo Belloc for useful comments on an earlier version of this work, the editors of JOIE and five anonymous referees who dedicated their quality time to the present paper. All remaining errors are our own. 


\section{References}

Acharya, V. V., R. P. Baghai, and K. V. Subramanian (2014), 'Wrongful Discharge Laws and Innovation', The Review of Financial Studies, 27(1): 301-346.

Akerlof, G. A. and J. L. Yellen (1986), Efficiency Wage Models of the Labor Market, Cambridge: Cambridge University Press.

Allen, M. M. (2013), 'Comparative Capitalisms and the Institutional Embeddedness of Innovative Capabilities', Socio-Economic Review, 11(4): 771-794.

Altuzarra, A. and F. Serrano (2010), 'Firms' Innovation Activity and Numerical Flexibility', Industrial and Labor Relations Review, 63(2): 327-339.

Antonelli, C. and F. Quatraro (2013), 'Localized Technological Change and Efficiency Wages across European Regional Labour Markets', Regional Studies, 47(10): 1686-1700.

Aoki, M. (1994), 'The Contingent Governance of Teams: Analysis of Institutional Complementarity', International Economic Review, 35(3): 657-676.

Aoki, M. (2001), Toward a Comparative Institutional Analysis, Cambridge: MIT Press.

Arvanitis, S. (2005), 'Modes of Labor Flexibility at Firm Level: Are There any Implications for Performance and Innovation?', Industrial and Corporate Change, 14(6): 993-1016.

Bassanini, A. and E. Ernst (2002), 'Labor Market Regulation, Industrial Relations and Technological Regimes: A Tale of Comparative Advantage', Industrial and Corporate Change, 11(3): 391-426.

Beer, M., B. Spector, P. R. Lawrence, D. Q. Mills, and E. Walton (1984), Managing Human Assets, New York: Macmillan.

Bellani, D. and G. Bosio (2019), 'Knockin' on Heaven's Door? Reframing the Debate on Temporary Employment and Wages: Evidence From Europe', Socio-Economic Review, 0(0): 1-39.

Belloc, F. (2019), 'Institutional Complementarities Between Labour Laws and Innovation', Journal of Institutional Economics, 15(2): 235-258.

Belloc, F., G. Burdin, L. Cattani, W. Ellis, and F. Landini (2020), Coevolution of job automation risk and workplace governance, University of Siena Working Paper, no. 841.

Belot, M., J. Boone, and J. Van Ours (2007), 'Welfare-Improving Employment Protection', Economica, 74(295): $381-396$.

Berton, F. and P. Garibaldi (2012), 'Workers and Firms Sorting into Temporary Jobs', The Economic Journal, 122(562): F125F154.

Berton, F., M. Richiardi, and S. Sacchi (2012), The Political Economy of Work, Security and Flexibility: Italy in Comparative Perspective, Bristol: The Policy Press.

Beugelsdijk, S. (2008), 'Strategic Human Resource Practices and Product Innovation', Organization Studies, 29(06): 821-847.

Boeri, T. and P. Garibaldi (2007), 'Two Tier Reforms of Employment Protection: A Honeymoon Effect?', The Economic Journal, 117: F357-F385.

Bos-Nehles, A., M. Renkema, and M. Janssen (2017), 'HRM and Innovative Work Behaviour: A Systematic Literature Review', Personnel Review, 46(7): 1228-1253.

Bowles, S. (1985), 'The Production Process in a Competitive Economy: Walrasian, Neo-Hobbesian, and Marxian Models', The American Economic Review, 75(1): 16-36.

Braverman, H. (1974), Labour and Monopoly Capital, New York: Monthly Review Press.

Cefis, E. and O. Marsili (2006), 'The Role of Innovation in Firms' Survival', Research Policy, 35(5): 626-641.

Chirinko, R. and D. J. Wilson (2008), 'State Investment Tax Incentives: A Zero-sum Game?', Journal of Public Economics, 92 (12): 2362-2384.

Coase, R. H. (1937), 'The Nature of the Firm', Economic, 4(16): 386-405.

Collins, H. (2006), 'Flexibility and Stability of Expectations in the Contract of Employment', Socio-Economic Review, 4(1): 139-153.

Crépon, B., E. Duguet, and J. Mairesse (1998), 'Research, Innovation and Productivity: An Econometric Analysis at the Firm Level', Economics of Innovation and New Technology, 7(2): 115-158.

Damiani, M., F. Pompei, and A. Ricci (2020), 'Labour Shares, Employment Protection and Unions in European Economies', Socio-Economic Review, 18(4): 1001-1038.

Deakin, S., P. Lele, and M. Siems (2008), 'The Evolution of Labour Law: Calibrating and Comparing Regulatory Regimes', International Labor Review, 146(3-4): 133-162.

Dekker, R., A. Kleinknecht, and H. Zhou (2011), 'Flexible Labor and Innovation Performance: Evidence From Longitudinal Firm-Level Data', Industrial and Corporate Change, 20(3): 941-968.

Dessein, W. and T. Santos (2006), 'Adaptive Organizations', Journal of Political Economy, 114(5): 956-995.

Dilli, S. (2019), 'The Diversity of Labor Market Institutions and Entrepreneurship', Socio-Economic Review, published online https://doi.org/10.1093/ser/mwz027.

Dosi, G., R. Freeman, M. Pereira, A. Roventini, and M.E. Virgillito (2020), 'The Impact of Deunionization on the Growth and Dispersion of Productivity and Pay', Industrial and Corporate Change, forthcoming. dtaa025, https://doi.org/10.1093/icc/ dtaa025

Earle, J., U. Pagano, and M. Lesi (2006), 'Information Technology, Organizational Form, and Transition to the Market', Journal of Economic Behavior and Organization, 60(4): 471-489. 
Eurofound (2020), Labour Market Change: Trends and Policy Approaches Towards Flexibilization, Luxembourg: Publications Office of the European Union.

European Commission (2010), Employment in Europe, Luxembourg: Publications Office of the European Union.

Foss, N.J. (1997), 'Resources and Strategy: Problems, Open Issues, and Ways Ahead', in N.J. Foss (ed.), Resources, Firms and Strategies: A Reader in the Resource-Based Perspective, Oxford: Oxford University Press, pp. 345-365.

Franceschini, F. and V. Mariani (2015), 'Flexible Labor and Innovation in the Italian Industrial Sector', Industrial and Corporate Change, 25(4): 1-16.

Ganotakis, P. (2012), 'Founders' Human Capital and the Performance of UK new Technology-Based Firms', Small Business Economics, 39(2): 495-515.

Griliches, Z. (1984), RÆD, Patents, and Productivity, Chicago: University of Chicago Press.

Grinza, E. and F. Quatraro (2019), 'Workers' Replacements and Firms' Innovation Dynamics: New Evidence From Italian Matched Longitudinal Data', Research Policy, 48(9): 1-18.

Guarascio, D., A. Cetrulo, and V. Cirillo (2019), 'Weaker Jobs, Weaker Innovation. Exploring the Effects of Temporary Employment on New Products', Applied Economics, 51(59): 6350-6375.

Gürpinar, E. (2016), 'Institutional Complementarities, Intellectual Property Rights and Technology in the Knowledge Economy', Journal of Institutional Economics, 12(3): 565-578.

Hall, P. A. and D. W. Soskice (2001), Varieties of Capitalism: The Institutional Foundations of Comparative Advantage, Oxford: Oxford University Press.

Haneda, S. and K. Ito (2018), 'Organizational and Human Resource Management and Innovation: Which Management Practices are Linked to Product and/or Process Innovation?', Research Policy, 47(1): 194-208.

Herrmann, R. A. (2008), 'Rethinking the Link Between Labour Market Flexibility and Corporate Competitiveness: A Critique of the Institutionalist Literature', Socio-Economic Review, 6(4): 637-669.

Houseman, S. N. (2001), 'Why Employers Use Flexible Staffing Arrangements: Evidence from an Establishment Survey', Industrial and Labor Relations Review, 55(1): 149-170.

Hoxha, S. and A. Kleinknecht (2020), 'When Labour Market Rigidities are Useful for Innovation. Evidence from German IAB Firm-Level Data', Research Policy, 49(7): 104066.

Jaffe, A. B. (1989), 'Real Effects of Academic Research', The American Economic Review, 79(5): 957-970.

Kleinknecht, A., F. N. van Schaik, and H. Zhou (2014), 'Is Flexible Labour Good for Innovation? Evidence from Firm-Level Data', Cambridge Journal of Economics, 38(5): 1207-1219.

Kochan, T. A. and P. Osterman (1994), The Mutual Gains Enterprise, Cambridge, MA: Harvard University Press.

Kräkel, M. (2016), 'Human Capital Investments and Work Incentives', Journal of Economics and Management Strategy, 25(3): 627-651.

Kristal, T. and Y. Cohen (2017), 'The Causes of Rising Wage Inequality: The Race Between Institutions and Technology', Socio-Economic Review, 15(1): 187-212.

Kuhlmann, S. and J. Edler (2003), 'Scenarios of Technology and Innovation Policies in Europe: Investigating Future Governance', Technological Forecasting \& Social Change, 70(7): 619-637.

Landini, F. (2013), 'Institutional Change and Information Production', Journal of Institutional Economics, 9(3): 257-288.

Landini, F. and U. Pagano (2018a), 'Stakeholders' Conflicts and Corporate Assets: An Institutional Meta-Complementarities Approach', Socio-Economic Review, 18(1): 1-28.

Landini, F. and U. Pagano (2018b), 'The Evolution of Corporate Species', in C. Driver and G. Thompson (eds), Corporate Governance in Contention, Oxford: Oxford University Press, pp.152-175.

Laursen, K. and N. J. Foss (2003), 'New Human Resource Management Practices, Complementarities and the Impact on Innovation Performance', Cambridge Journal of Economics, 27(2): 243-263.

Leiponen, A. (2005), 'Skills and Innovation', International Journal of Industrial Organization, 23(5-6): 303-323.

Lorenz, E. H. (1999), 'Trust, Contract and Economic Cooperation', Cambridge Journal of Economics, 23(3): $301-316$.

Lucidi, F. and A. Kleinknecht (2010), 'Little Innovation, Many Jobs: An Econometric Analysis of the Italian Labour Productivity Crisis', Cambridge Journal of Economics, 34(3): 525-546.

Lundvall, B- $\AA$ (1992), National Innovation Systems: Towards a Theory of Innovation and Interactive Learning, London: Pinter.

Malgarini, M., M. Mancini, and L. Pacelli (2013), 'Temporary Hires and Innovative Investments', Applied Economics, 45(17): 2361-2370.

Manso, G. (2011), 'Motivating Innovation', Journal of Finance, 66(5): 1823-1860.

March, J. G. (1991), 'Exploration and Exploitation in Organizational Learning', Organization Science, 2(1): 71-87.

Marglin, S. (1974), 'What do Bosses do?', Review of Radical Political Economy, 6(2): 60-112.

Marton, F. and R. Säljö (1976), 'On Qualitative Differences in Learning: 1 - Outcome and Process', The British Journal of Educational Psychology, 46(1): 4-11.

Michie, J. and M. Sheehan (2001), 'Labour Market Flexibility, Human Resource Management and Corporate Performance', British Journal of Management, 12(4): 287-306. 
Michie, J. and M. Sheehan (2003), 'Labour Market Deregulation, "Flexibility" and Innovation', Cambridge Journal of Economics, 27(1): 123-143.

Milgrom, P. and J. Roberts (1990), 'The Economics of Modern Manufacturing: Technology, Strategy and Organization', The American Economic Review, 80(3): 511-528.

Moretti, E. and D. J. Wilson (2014), 'State Incentives for Innovation, Star Scientists and Jobs: Evidence From Biotech', Journal of Urban Economics, 79(C): 20-38.

Nelson, R. (1993), National Innovation Systems. A Comparative Analysis, Oxford: Oxford University Press.

Nelson, R. R. and S. G. Winter (1982), An Evolutionary Theory of Economic Change, Cambridge: Harvard University Press.

Nicita, A. and U. Pagano (2016), 'Finance-technology Complementarities: An Organizational Equilibria Approach', Structural Change and Economic Dynamics, 37(C): 43-51.

North, D. (1990), Institutions, Institutional Change and Economic Performance, Cambridge: Cambridge University Press.

OECD (1997), National System of Innovation, Paris: OECD Publishing.

Pagano, U. (1993), 'Organizational Equilibria and Institutional Stability', in S. Bowles, H. Gintis and B. Gustafsson (eds), Markets and Democracy: Participation, Accountability and Efficiency, Cambridge: Cambridge University Press, pp. 83-115.

Pagano, U. (2011), 'Interlocking Complementarities and Institutional Change', Journal of Institutional Economics, 7(3): 373-392.

Pagano, U. and M. A. Rossi (2004), 'Incomplete Contracts, Intellectual Property and Institutional Complementarities', European Journal of Law and Economics, 18(1): 55-67.

Pagano, U. and R. Rowthorn (1994), 'Ownership, Technology and Institutional Stability', Structural Change and Economic Dynamics, 5(2): 221-242.

Pagano, U. and M. Vatiero (2015), 'Costly Institutions as Substitutes: Novelty and Limits of the Coasian Approach', Journal of Institutional Economics, 11(2): 265-281.

Penrose, E. (1959), The Theory of the Growth of the Firm, Oxford: Blackwell Publishing.

Polavieja, J. G. (2005), 'Flexibility or Polarization? Temporary Employment and Job Tasks in Spain', Socio-Economic Review, 3 (2): 233-258.

Ribeaux, P. and S. E. Poppleton (1978), Psychology of Work: An Introduction, London: Macmillan.

Saint-Paul, G., C. R. Bean and G. Bertola (1996), 'Exploring the Political Economy of Labour Markets Institutions', Economic Policy, 11(23): 263-315.

Scarpetta, S. and T. Tressel (2004), 'Boosting productivity via innovation and adoption of new technologies: any role for labour market institutions?', Policy Research Working Paper Series, no. 3273, World Bank.

Schneider, L., J. Gunther, and B. Brandenbury (2010), 'Innovation and Skills from a Sectoral Perspective: A Linked Employer-Employee Analysis', Economics of Innovation and New Technology, 19(2): 185-202.

Shapiro, C. and J. E. Stiglitz (1984), 'Equilibrium Unemployment as a Worker Discipline Device', The American Economic Review, 74(3): 433-444.

Shipton, H., M. A. West, J. Dawson, K. Birdi and M. Patterson (2006), 'HRM as a Predictor of Innovation', Human Resource Management Journal, 16(1): 3-27.

Slaper, T. F., N. R. Hart, T. J. Hal, and M. F. Thompson (2011), 'The index of Innovation: A New Tool for Regional Analysis', Economic Development Quarterly, 25(1): 36-53.

Svensson, S. (2011), 'Flexible Working Conditions and Decreasing Levels of Trust', Employee Relations, 34(2): $126-137$.

Vatiero, M. (2017), 'Learning from the Swiss Corporate Governance Exception', KYKLOS, 70(2): 330-343.

Wachsen, E. and K. Blind (2016), 'More Labour Market Flexibility for More Innovation? Evidence from Employer-Employee Linked Micro Data', Research Policy, 45(5): 941-950.

Williamson, O. E. (1985), The Economic Institutions of Capitalism, New York: The Free Press.

Cite this article: Dughera S, Quatraro F, Vittori C (2022). Innovation, on-the-job learning, and labor contracts: an organizational equilibria approach. Journal of Institutional Economics 18, 605-620. https://doi.org/10.1017/S1744137421000497 